http://jmscr.igmpublication.org/home/

ISSN (e)-2347-176x ISSN (p) 2455-0450

crossref DOI: https://dx.doi.org/10.18535/jmscr/v8i11.50

Journal Of Medical Science And Clinical Research

IGM Publication

An Official Publication of IGM Publication

\title{
Comparison of Intrathecal Chloroprocaine 1\% Vs Levobupivacaine 0.5\% in Patient for Lower Limb Surgery
}

\author{
Authors \\ Dr Rachit Sinha ${ }^{1}$, Dr Akash Gupta ${ }^{2 *}$, Dr Neeharika Arora ${ }^{3}$, Dr Malti Agarwal ${ }^{4}$, \\ Dr Rampal Singh ${ }^{5}$, Dr Ishan Verma ${ }^{6}$ \\ ${ }^{1}$ Junior Resident, Department of Anaesthesiology, Rohilkhand Medical College, Bareilly \\ ${ }^{2}$ Assistant Professor, Department of Anaesthesiology, Rohilkhand Medical College, Bareilly \\ ${ }^{3}$ Professor, Department of Anaesthesiology, Rohilkhand Medical College, Bareilly \\ ${ }^{4}$ Professor and Head of Department, Department of Anaesthesiology, Rohilkhand Medical College, Bareilly \\ ${ }^{5}$ Professor, Department of Anaesthesiology, Rohilkhand Medical College, Bareilly \\ ${ }^{6}$ Junior Resident, Department of Anaesthesiology, Rohilkhand Medical College, Bareilly \\ *Corresponding Author \\ Dr Akash Gupta \\ Assistant Professor, Department of Anaesthesiology, Rohilkhand Medical College, Bareilly

Abstract
Background and Aims: With the advent of newer drug in spinal Anaesthesia, there is a lacuna in the study of
these drugs. Use of longer acting Local Anaesthetics in lower dose has been the practice for shorter Surgery. The
study aims to compare Chloroprocaine with the Levobupivacaine in lower limb surgeries of shorter duration.
Methods: A Prospective, Comparative study was conducted after obtaining the permission from Ethical
Committee. A total of 70 patients (men \& women, $18-60$ years, ASA 1-2) posted for elective lower long surgery
were included. They were randomly divided into 2 groups. Group A received $1 \%$ Chloroprocaine $3 m l$ ( $30 \mathrm{mg})$
while Group B received $0.5 \%$ Levobupivacaine $3 \mathrm{ml}$ (15mg). The Onset of sensory blockade and motor blockade,
Peak height for sensory block, two-segment regression time, Duration of sensory block and motor block were
studied.
Results: The Onset of sensory blockade \& motor blockade was similar in both the groups. The Peak height for
sensory block was higher in Group B (T4 - T6 vs T6 - T8) as compared from Group A, and it also had a longer
two-segment regression time (119.31 \pm 34.87 mins vs $43.06 \pm 8.75$ min). The duration of sensory block was shorter
in Group A (74.43 \pm 10.96 mins vs $312.71 \pm 51.94$ mins). The duration of motor block was shorter in Group A
(61.03 \pm 11.48 mins vs $249.57 \pm 38.34$ mins). All the differences were statistically significant (p<0.05)
Conclusion: We conclude Chloroprocaine is better for shorter lower limb and ambulatory surgery.

\section{Introduction}

Spinal Anaesthesia is the most common neuraxial block used for surgery. It provides excellent surgical conditions for lower abdominal \& lower limb procedures. Local Anaesthetic (LA) is the main stay of the Spinal Anaesthesia. There are complications with longer acting Local Anaesthetic agents like delayed ambulation, risk of urinary retention, TNS, hypotension, increased failure rate. ${ }^{[1]}$ Further study of the ideal short acting spinal LA is required for the shorter procedure, day care and ambulatory surgery. ${ }^{[2]}$

Chloroprocaine was first used by Foldes and McNall in 1952. It is an amino-ester with a very short half-life. Reports of persistent neurological deficit and adhesive arachnoiditis with Spinal Chloroprocaine had led to complete withdrawal of the drug in early 1980s. ${ }^{[3]}$ The historical usage in epidural anaesthesia for obstetric patients, had reports of neurological deficit mostly owing to 
unintentional intrathecal injection of large volume of Chloroprocaine. ${ }^{5}$ Chloroprocaine has a very rapid onset, short acting, faster resolution leading to lesser side effect. The earlier toxicity was attributed to the Sodium Bisulfite ${ }^{[3]}$, which was added as a preservative. So, a newer $\mathrm{pH}$ adjusted, preservative $\&$ anti-oxidant free formulation has been released in 2004 and is being used worldwide. $^{[4]}$

Levobupivacaine was introduced much later in 1980s, Levobupivacaine is a pure S (-) enantiomer of racemic Bupivacaine and is lesser cardiotoxic. Nevertheless, majority of the studies have found no significant difference between Levobupivacaine and Bupivacaine. [8] Levobupivacaine is a Longer acting local Anaesthetic drug, and in absence of an ideal shorter acting Anaesthetic agent, low dose Levobupivacaine is being used in shorter duration surgeries. The lower doses of Levobupivacaine have shown to have differential neuraxial block which has preserved motor function, which might not be very conducive for the lower limb surgery. A Shorter duration Surgery calls for rapid onset, quicker recovery of the Anaesthesia, as the prolonged effect leads to increased duration of close monitoring in Post-op ward, risk of altered hemodynamic stability, delayed micturition, delayed ambulation and lastly delayed discharge. [6]

Many studies have been done on the comparison of the both the drugs in different study. However, there is a lacuna when we look for studies comparing these 2 drugs. There is no study directly comparing the effects of the Chloroprocaine and Levobupivacaine. The longer acting drugs been used in lower volume in shorter surgeries, but this leads to variable effect and many difficulties arises as enumerated. Shorter surgeries with quicker surgical readiness and earlier discharge is the demand on the modern times. Therefore, a study on shorter surgeries was selected.

The formulation of Chloroprocaine available in India is $1 \%$ when compared from those outside
India which are $2 \%$. The study conducted previously has been with $2 \%$ Chloroprocaine in a western population. There are limited study on 30mg dosage, while higher doses has been studied. The minimal effective dose for Chloroprocaine has been $30 \mathrm{mg}$ so a minimum volume required for surgery with $1 \%$ is $3 \mathrm{ml}$. The dosage of drugs below $30 \mathrm{mg}$ has not been effective in lower limb surgery for duration $>60$ mins. ${ }^{[7]}$

The lower doses of longer acting local anaesthetic drugs has a variable effect, which is not suitable for surgery. The minimal effective dose of $0.5 \%$ Levobupivacaine has been shown as $11.7 \mathrm{mg}^{[8]}$, therefore a $0.5 \% 2.5 \mathrm{ml}$ drug was sufficient to conduct surgery. To rule out any discrepancy arising due to variation in the result, the volume of the comparing drugs even was made even. Levobupivacaine is also Isobaric, similar to that of Chloroprocaine, so reducing another factor of discrepancy in the result.

Therefore, we conducted the study on comparison of $1 \%$ Isobaric Chloroprocaine $3 \mathrm{ml}$ with $0.5 \%$ Isobaric Levobupivacaine $3 \mathrm{ml}$ in shorter surgeries of lower abdomen or lower limb was conducted. The Aim of the study is to compare onset of sensory and motor block, duration of sensory and motor block, peak height of sensory block, two segment regression time, hemodynamic changes, any side effects.

\section{Subjects and Methods}

Following approval by the Board of Thesis/Research committee, the study was conducted between January 2019 to December 2019. A total of 70 patients was randomly divided in two groups in 1:1 allocation ratio, each comprising 35 patients [Figure 1]. Consent and approval of patient for participation in study was taken. Thorough pre-Anaesthetic check-up was done one day prior to the surgery and informed written consent for participation in the study was taken.

The patients were randomly divided into two groups: Group "A" and "B". In Group A, patients were given $1 \%$ Chloroprocaine $3 \mathrm{ml}$ (30mg) 
intrathecally, while in Group B, $0.5 \%$ Levobupivacaine $3 \mathrm{ml} \quad(15 \mathrm{mg})$ were given intrathecally. Drugs were prepared by the anaesthetist who was not involved in the observation. They were kept NPO for 8 hrs \& Tab Ranitidine 150mg and Tab Alprazolam $0.25 \mathrm{mg}$ was given orally, the night before surgery.

On the day of surgery, intravenous line was secured and iv fluid Ringer Lactate was started at the rate of $15 \mathrm{ml} / \mathrm{kg} 30 \mathrm{~min}$ before surgery and maintenance fluid as per Holliday Segar formulae. Monitor was attached and baseline readings were taken. Patient was premedicated with Inj. Ranitidine 50mg iv, Inj. Ondansetron 4mg iv, and heart rate, systolic blood pressure, diastolic blood pressure, mean arterial pressure, arterial oxygen saturation and ECG was recorded.

Spinal Anaesthesia was administered to the patient in L2-L3 interspace with patient sitting using a midline approach using $25 \mathrm{G}$ spinal needle. According to randomization, patient received either preservative free $\&$ bisulfite free formulation of isobaric $1 \%$ Chloroprocaine $30 \mathrm{mg}$ $(3 \mathrm{ml})$ or isobaric $0.5 \%$ Isobaric Levobupivacaine $15 \mathrm{mg}(3 \mathrm{ml})$. No adjuvant medication was added to either local Anaesthetic.

After completion of the spinal injection, patient was immediately made to lie supine. The patient was evaluated for sensory and motor block, for every 2 mins for first 20 mins, then every 3 mins for next 30 mins, then every 5 mins for next 40 mins, then every 10 mins for $60 \mathrm{mins}$, and finally every 15 mins until the sensory block has regressed to $\mathrm{S} 1$ dermatome. The patient will be administered Inj Midazolam 1mg iv after spinal Anaesthesia has been given. During the surgery the patient's pulse, Systolic Blood pressure, Diastolic Blood pressure, Mean Arterial Pressure, arterial oxygen saturation will be recorded every 3 mins for 30 mins and then every 5 mins until completion of the surgery.

The sensory level of the block was assessed in a caudal to cephalad direction, using loss to pin prick sensation, and the C5-C6 dermatome was used as an unblocked reference point. The motor
Block was assessed using the Modified Bromage Scale. ${ }^{[9]}$

Readiness for surgery was defined as loss of pin prick sensation $\geq \mathrm{T} 10$ with modified Bromage $\geq 2$.

During surgery, evaluation of the motor block was suspended until the end of the procedure. If the patient complained of pain, Inj Butorphanol $1 \mathrm{mg}$ iv was administered. If additional sedation was needed, midazolam $1 \mathrm{mg}$ iv was administered. The total dose of any given medication was recorded. If the patient still felt pain, general Anaesthesia was provided and the study was stopped. Any complications, side effects and adverse effects up to $24 \mathrm{hrs}$ postoperatively were noted.

Clinically relevant hypotension (defined as a decrease in systolic arterial blood pressure $\geq 30 \%$ from baseline values) was initially be treated with a rapid iv infusion of 300ml Ringers Lactate solution over $5 \mathrm{~min}$ period. If this was found to be ineffective, Inj Mephentermin $6 \mathrm{mg}$ iv was given. Occurrence of clinically relevant bradycardia (defined as reduction in Heart Rate $\leq 45$ ) was treated with Inj Atropine $0.4 \mathrm{mg}$ iv.

\section{Statistical Analysis}

The data from the present study was systematically collected, compiled and statistically analysed. Descriptive \& inferential statistical analysis were derived from results on continuous measurements, presented as mean $\pm \mathrm{SD}$ while results on categorical measurements were presented in numbers (\%age). Student t test was used to find the significance of the study parameters on a continuous scale between 2 groups (intergroup analysis).

The $\mathrm{p}$ value was determined to evaluate the level of significance, $\mathrm{p}<0.05$ was considered as significant at $5 \%$ significance level, while $\mathrm{p}<0.01$, significant at $1 \%$ was considered as highly significant.

Chi square/ Fisher's exact test was used to find the significance of the study parameters on the categorical scale where ever applicable between 2 or more groups. The statistical data analysis and graphs were generated by Microsoft Excel 2016 \& 
Microsoft Word 2016 was used to generate charts and tables.

\section{Result}

Out of the 84 patients assessed, only 70 were included for final analysis [Figure 1]. The Age, Weight, Gender, were comparable in both the groups. [Table 1]

The onset of both sensory and motor block was faster is Group A. The time to peak sensory block was also earlier in Group A but it attained a lower dermatomal blockade as compared to Group B. The duration of both sensory and motor blockade was longer in Group B. The two-segment regression time was also shorter in Group A. The differences were statistically significant in all the parameter $(p>0.05)$. [Table 2]

In group B, 4 patients had hypotension, and 2 had Bradycardia while there was no hypotension or bradycardia in Group A. shivering was complained by 3 patients in Group B as compared from 1 in Group A.One patient complained of Nausea in both the group.

The hemodynamic was more stable in Group A compared from Group B, there was a greater fall in MAP after 6 min of spinal anaesthesia in Group

A. [Figure 3]

Figure 1: Consort Diagram

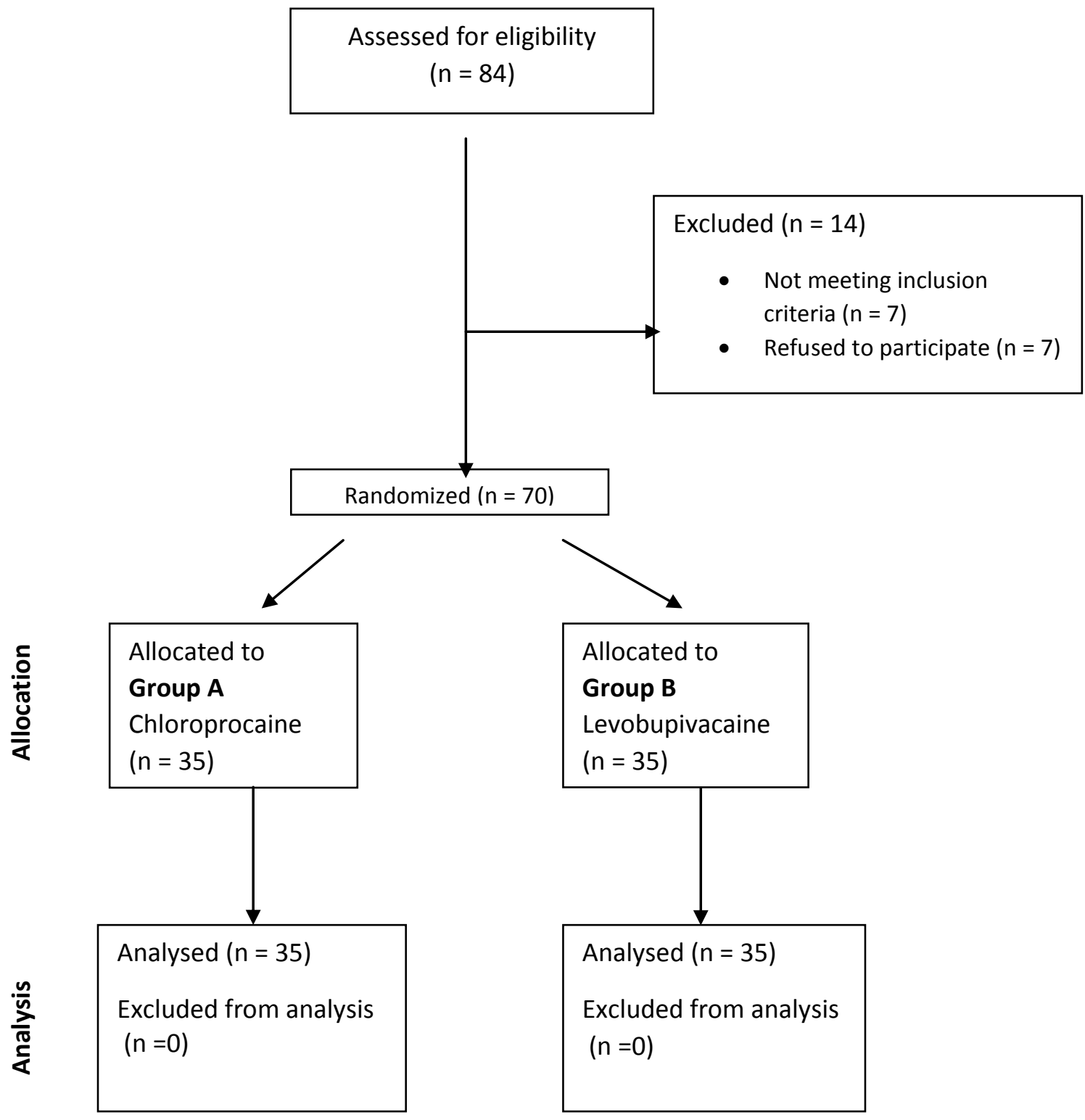


Table-1: Comparison of Age, Weight and Gender In Between Group A and Group B.

\begin{tabular}{|l|c|c|c|}
\hline & GROUP A & GROUP B & $\boldsymbol{p}$-value \\
\hline AGE & $40.71 \pm 11.95$ & $39.63 \pm 13.14$ & $0.72 \#$ \\
\hline WEIGHT & $58.86 \pm 8.61$ & $62.09 \pm 8.79$ & $0.1251 \#$ \\
\hline MALE & $25(71.4 \%)$ & $27(77.1 \%)$ & \multirow{2}{*}{$0.584 \#$} \\
\hline FEMALE & $10(28.6 \%)$ & $8(22.9 \%)$ & \\
\hline
\end{tabular}

\#statistically not significant. $(p>0.05)$

Table-2: Spinal Block Characteristics in Group A and Group B

\begin{tabular}{|c|c|c|c|}
\hline & $\begin{array}{l}\text { GROUP A } \\
\text { (in mins) } \\
\text { MEAN } \pm \text { SD }\end{array}$ & $\begin{array}{l}\text { GROUP B } \\
\text { (in mins) } \\
\text { MEAN } \pm \text { SD }\end{array}$ & $p$-Value \\
\hline \multicolumn{4}{|l|}{ Sensory Block } \\
\hline Onset of sensory blockade & $4.8 \pm 1.1$ & $6.89 \pm 1.97$ & $<0.0001 *$ \\
\hline Time of Peak height for sensory block & $11.11 \pm 4.99$ & $14.26 \pm 3.19$ & $0.0025 *$ \\
\hline Duration of sensory & $74.43 \pm 10.96$ & $312.71 \pm 51.94$ & $<0.0001 *$ \\
\hline 2-segment regression time & $43.06 \pm 8.75$ & $119.31 \pm 34.87$ & $<0.0001 *$ \\
\hline \multicolumn{4}{|l|}{ Motor Block } \\
\hline Onset of motor blockade & $7.40 \pm 1.5$ & $10.91 \pm 3.47$ & $<0.0001 *$ \\
\hline Duration of motor block & $61.03 \pm 11.48$ & $249.57 \pm 38.34$ & $<0.0001 *$ \\
\hline
\end{tabular}

*statistically significant. $(p<0.05)$

Figure-2: Graphical representation of Mean of Peak Sensory Block in Group A and Group B

PEAK SENSORY BLOCK



Figure-3: Graphical representation of Mean of Heart Rate and Mean Arterial Pressure in Group A and Group B

HR and MAP Comparision

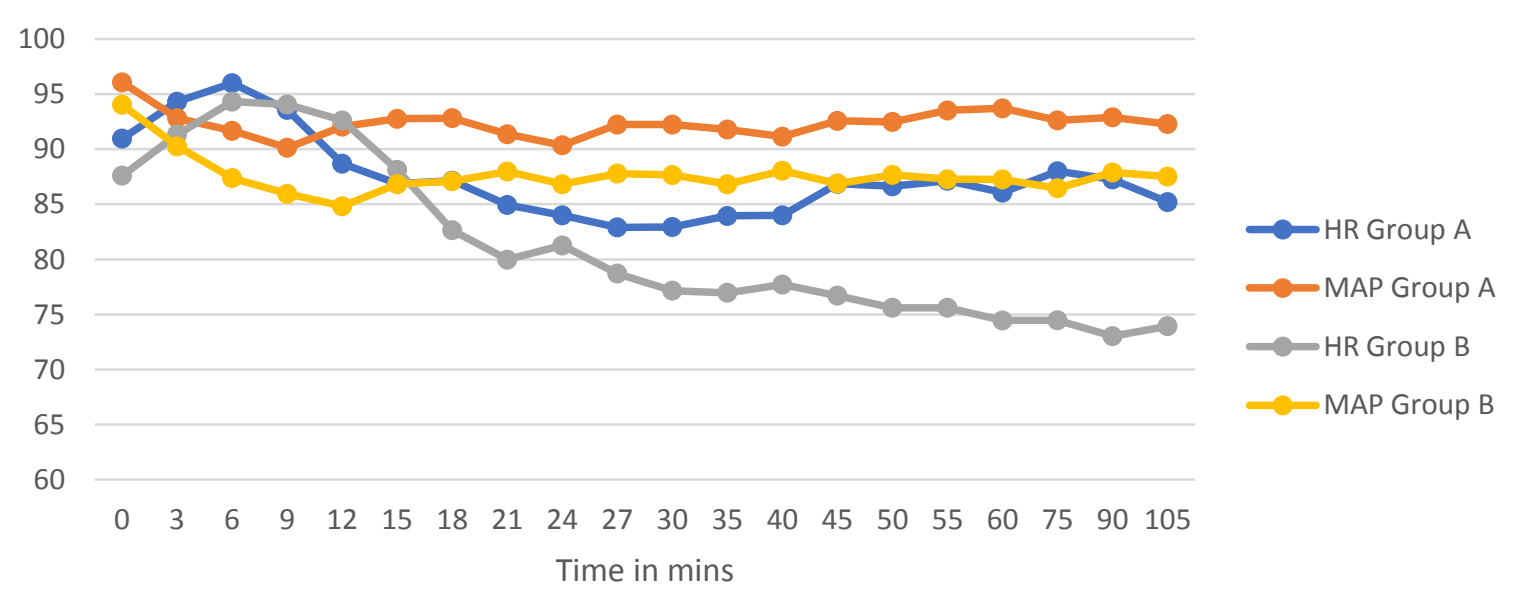


Table-3 Comparison of Side Effect in between group A and Group B.

\begin{tabular}{|l|c|c|}
\hline Side Effect & Group A & Group B \\
\hline TNS & 0 & 0 \\
\hline Hypotension & 0 & 4 \\
\hline Bradycardia & 0 & 2 \\
\hline Nausea & 1 & 1 \\
\hline Vomiting & 0 & 0 \\
\hline Respiratory Depression & 0 & 0 \\
\hline Pruritus & 0 & 0 \\
\hline Shivering & 1 & 3 \\
\hline
\end{tabular}

\section{Discussion}

Day Care Surgeries are the latest trend and the patients do not wish to lose work. They prefer to resume their day today activities at the earliest with minimal dependency on another person. A faster recovery for the patients not only benefits the patients but also reduces the burden from the already overburdened health care services in our country.

Quest for an Ideal anaesthetic agents has been on and this gives us various drugs with different aspects. As none of the local anaesthetic agents can be used in all the surgeries, the time demands different a more suitably acting drug which covers all aspects of the surgery and does not over drives the requirement.

The central neuraxial blockade depends on the patient factors \& the spread of the drug. The Patient factors include age, height, position, spinal column configuration, CSF volume. The factors governing the spread of the drug include amount, volume, specific gravity, density, baricity of solution, potency of the drug used. The level at which the drug is administered, rate of administration of drug, Barbotage technique. Following administration of the drug, there is fall in administration of the concentration which in turn depends upon dilution and mixing in CSF, diffusion and distribution to neural tissues, uptake and fixation by neural tissues, vascular absorption and elimination through arachnoid villi and directly from capillary bed of parenchyma.

All these factors determine onset of sensory blockade, onset of motor blockade, peak height for sensory block, two-segment regression time, duration of sensory block, duration of motor block. For example, selection of a higher level used for spinal anaesthesia achieves a greater sensory and motor blockade. A higher drug concentration and dose will have more profound block. A faster rate of the administration of the drug, will have a higher block as compared to the lower rate of administration.

In our study, the dose of Chloroprocaine was selected to be $30 \mathrm{mg}$ as there were limited number of studies conducted at this dosage. Most of the studies had been conducted on 40mg\& 50mg. Given the limited number of studies, there was limited clarity on the feasibility of the usefulness of the selected drug dosage. Casati et al [7] concluded that the Chloroprocaine $30 \mathrm{mg}$ had insufficient duration of spinal blockade and suggested adding adjuvants. Kopacz et $a l^{[10]}$ concluded that the $10 \mathrm{mg}$ is a no effect dose, $20 \mathrm{mg}$ and $30 \mathrm{mg}$ produced adequate sensory anaesthesia but limited motor blockade with occasional sacral sparing. Therefore, we selected the lowest dose of 30mg 1\% Chloroprocaine $3 \mathrm{ml}$ for patients planed for lower limb surgery, in view that this dose could be sufficient for surgical anaesthesia.

The mean heart rate rose following administration of spinal anaesthesia in both the group which was more in Group B but not statistically significant. After 21 mins of anaesthesia the heart rate started to decline, but the decline was more statistically significant in group B after 30 mins compared from group A.

The mean onset time of sensory blockade was significantly early in Group A (4.8mins) as compared with Group B (6.89mins) and the difference was statistically significant $(p<0.0001)$. However, there was a statically significant faster onset of sensory block, the actual benefit in clinical practise is debatable.

The study conducted by Forster et $a l^{[11]}$ and Lacasse et al ${ }^{[3]}$ on 2\% Chloroprocaine 40mg had an onset of sensory block was similar to our study $\&$ we also saw similar result in Siddaiah et al ${ }^{[12]}$. While Davis et $a l^{[13]}$ had a different mean sensory block onset time of less than 10 mins, but they had 
a small sample size of 8 patients and the exact time was not mentioned. The study conducted by other authors ${ }^{[14,15]}$ on $0.5 \%$ Levobupivacaine $15 \mathrm{mg}$ had similar results. While few author $[16,17,18]$ using other doses of Levobupivacaine by had a different mean onset sensory block due to the dose variation.

The mean time of Peak height for sensory block was significantly early in Group A compared with Group B [Table 2] and the difference was statistically significant $(\mathrm{p}<0.002)$.

The study by Davis et $a l^{[13]}$ Chloroprocaine and Attri et al ${ }^{[19]}$ Vellosillo et al ${ }^{[17]}$ and other authors ${ }^{[20-}$ ${ }^{22]}$ on Levobupivacaine had similar results. While Siddaiah et $a l^{[12]}$ Camponovo et $a l^{[6]}$ with Chloroprocaine and Kataraia et al ${ }^{[14]}$ and Mantouvalou et $a l^{[16]}$ on Levobupivacaine had different results owing to different doses.

The comparison of peak height for sensory block was significantly higher in Group B as compared with Group A [Table 2] which was statistically significant $(p<0.00001)$. We saw that the patient receiving Levobupivacaine achieved a higher dermatomal blockade, also that the Chloroprocaine achieved a sufficient blockade for the lower limb surgeries.

The study by Various author ${ }^{[7,13,23,24]}$ found similar mean peak height of sensory block with 30mg Chloroprocaine. The study of Levobupivacaine $12.5 \mathrm{mg}$ byanother author $[17,18,22,25]$ all had a mean peak sensory block of T4. The mean duration of sensory block was significantly less in Group A compared with Group B and the difference was statistically significant $(\mathrm{p}<0.0001)$. [Table 2]. The study by Gonter et $a l^{[23]}$ and Davis et $a l^{[13]}$ had duration of regression of sensory block to S1 was similar to our study. The study conducted by various authors [26-28] on $0.5 \%$ Levobupivacaine $15 \mathrm{mg}$ had a similar mean duration of sensory block.

The mean duration of two segment regression of sensory block was significantly less in Group A compared with Group B and the difference was statistically significant $(\mathrm{p}<0.0001)$. [Table 2].
The study by Gonter et $a l^{[23]}$ and Smith et $a l^{[24]}$ on Chloroprocaine had a similar result. The study on 40mg Chloroprocaine by other authors ${ }^{[3,11,12,29,30]}$ had a different mean duration of two segment regression of sensory block readily attributed to the higher dose used in the study. The study by Burke et $a l^{[27]}$ and Kataraia et $a l^{[14]}$ on $0.5 \%$ of Levobupivacaine $15 \mathrm{mg}$ had a similar result, while Mantouvalou et $a l^{[16]}$ and Sahin et $a l^{[15}{ }^{]}$had a different mean duration of two segment regression, while Mantouvalou et $a l^{[16]}$ used L3-4 interspace for spinal anaesthesia, Sahin et al ${ }^{[15]}$ had the patient in prone position for the entire duration of the surgery.

The time to Onset of motor blockade was significantly less in Group A compared with Group B and the difference was statistically significant $(p<0.00001)$. [Table 2]. There was no study on $1 \%$ Chloroprocaine $30 \mathrm{mg}$, which showed the onset of motor block. The study on $0.5 \%$ Levobupivacaine $15 \mathrm{mg}$ by various authors ${ }^{[14,16,27,28]}$ had similar result.

The time of Duration of motor block was significantly less in Group A compared with Group B and the difference was statistically significant $(\mathrm{p}<0.00001)$ [Table 2]. The study on Chloroprocaine $30 \mathrm{mg}$ by Gonter et al ${ }^{[23]}$ found with Chloroprocaine the mean duration of motor block was 54 mins and the Gastrocnemius regained $90 \%$ of the power by 70 mins when tested with Isometric force Dynamometer, this is similar to our study. Davis et al ${ }^{[13]}$ had mean duration of motor block of $65 \mathrm{mins}$ with $3 \% \quad 30 \mathrm{mg}$ Chloroprocaine. The Gastrocnemius regained $90 \%$ of the power by $69 \mathrm{mins}$ when tested with Isometric force Dynamometer the results were similar to our study. The study with $0.5 \%$ Levobupivacaine $15 \mathrm{mg}$ by various author ${ }^{[15,16,27,28]}$ had similar result.

\section{Side effects}

Hypotension was not seen in Group A, while there were $11 \%$ patients in group B who had hypotension which was treated with Injection Mephentermin 6mg iv and 200-250ml boluses of iv fluids. It was significantly more in the Group B 
patient receiving Levobupivacaine [Table 3]. The mean arterial pressure was significantly lower in the Group B patients after the onset of sensory blockade. [Figure 3]

In the study of Chloroprocaine by Kouri et al ${ }^{[30]}$ there was mild hemodynamic changes and did not require vasoactive agents, sililar observation was made by other authors ${ }^{[7,23,29]}$

The study by Camponovo et al ${ }^{[6]}$, Lacasse et al ${ }^{[3]}$ and other authors ${ }^{[12,31]}$ on Chloroprocaine there was hypotension in $4.5-12 \%$ on the patients.

In the study of Levobupivacaine by Mantouvalou et al ${ }^{[16]}$ mean of Mean Arterial Pressure and Heart Rate steadily declined during the surgery and similar trend was seen by Fattorini et al ${ }^{[28]}$, Attri et al. ${ }^{[19]}$

The study by various author ${ }^{[14,16,18,19,25]}$ on Levobupivacaine had a hypotension from $5-17 \%$ of patients.

There was Bradycardia in 2 patients in Group B with heart rate falling below $45 / \mathrm{min}$ in which was $5 \%$ of the patients and none in Group A which was treated with Inj Atropine $0.4 \mathrm{mg}$ iv. [Table 3] In the study of Chloroprocaine by Kouri et al ${ }^{[30]}$ there was no bradycardia and similar observation was made by others ${ }^{[6,7,23,29]}$. While study by Siddaiah et al ${ }^{[12]}$ and other authors ${ }^{[3,31]}$ on Chloroprocaine, they had a bradycardia in few patients.

The study by various authors ${ }^{[14,18,19,25]}$ on Levobupivacaine showed Bradycardia in $3-15 \%$ of their patients.

There was no incidence of Transient Neurological Symptoms, Respiratory Depression, Pruritis in the either group.

\section{Conclusion}

The sensory and motor block by Chloroprocaine was adequate for shorter lower limb surgery. Thus, we conclude that Chloroprocaine is more suitable for shorter lower limb surgeries on comparing with Levobupivacaine. While levobupivacaine is more suitable for longer surgeries.

\section{References}

1. Ghisi D, Bonarelli S. Ambulatory surgery with chloroprocaine spinal anesthesia: a review. Ambulatory Anesthesia. 2015 Nov 2;2:111-20.

2. Förster JG. Short-acting spinal anesthesia in the ambulatory setting. Current Opinion in Anesthesiology. 2014 Dec 1;27(6):597-604.

3. Lacasse M, Roy J, Forget J, Vandenbroucke F, Seal R, Beaulieu D et al. Comparison of bupivacaine and 2-chloroprocaine for spinal anesthesia for outpatient surgery: a doubleblind randomized trial. Canadian Journal of Anesthesia/Journal canadiend'anesthésie. 2011;58(4):384-91.

4. Saporito A, Ceppi M, Perren A, La Regina D, Cafarotti S, Borgeat A, Aguirre J, Van De Velde M, Teunkens A. Does spinal chloroprocaine pharmacokinetic profile actually translate into a clinical advantage in terms of clinical outcomes when compared to low-dose spinal bupivacaine? A systematic review and meta-analysis. Journal of clinical anesthesia. 2019 Feb 1;52:99-104.

5. Miller R, Cohen N, Eriksson L, Fleisher L, Wiener-Kronish J, Young W. Miller's anesthesia. 8th ed. 2015. p. 1697

6. Camponovo C, Wulf $\mathrm{H}$, Ghisi D, et al. Intrathecal $1 \%$ 2-chloroprocaine vs $0.5 \%$ bupivacaine in ambulatory surgery: a prospective, observer-blinded, randomized, controlled trial. Acta Anaesthesiol Scand. 2014; 58(5):560-6.

7. Casati A, Danelli G, Berti M, Fioro A, Fanelli A, Benassi $\mathrm{C}$ et al. Intrathecal 2Chloroprocaine for Lower Limb Outpatient Surgery: A Prospective, Randomized, Double-Blind, Clinical Evaluation. Anesthesia \& Analgesia. 2006;103(1):2348.

8. Sell A, Olkkola KT, Jalonen J, Aantaa R. Minimum effective local anaesthetic dose of isobaric levobupivacaine and ropivacaine administered via a spinal catheter for hip 
replacement surgery. British journal of anaesthesia. 2005 Feb 1;94(2):239-42.

9. Miller R, Cohen N, Eriksson L, Fleisher L, Wiener-Kronish J, Young W. Miller's anesthesia. 8th ed. 2015. p. 1703

10. Kopacz DJ. Spinal 2-chloroprocaine: minimum effective dose. Reg Anesth Pain Med. 2005;30(1):36-42.

11. Förster JG, Rosenberg PH, Harilainen A, Sandelin J, Pitkänen MT. Chloroprocaine 40 mg produces shorter spinal block than articaine $40 \mathrm{mg}$ in day-case knee arthroscopy patients. Acta Anaesthesiologica Scandinavica. 2013 Aug;57(7):911-9.

12. Siddaiah J, Pujari VS, Madalu AS, Bevinaguddaiah Y, Parate LH. A comparative study on the effect of addition of intrathecal buprenorphine to 2chloroprocaine spinal anesthesia in short duration surgeries. Journal of Anaesthesiology, Clinical Pharmacology. 2019 Oct;35(4):533-9

13. Davis BR, Kopacz DJ. Spinal 2chloroprocaine: the effect of added clonidine. AnesthAnalg. 2005;100(2):55965

14. Kataria AP, Jarewal V, Kumar R, Kashyap A. Comparison of levobupivacaine and levobupivacaine with dexmedetomidine in infraumbilical surgeries under spinal anesthesia. Anesthesia, essays and researches. 2018 Jan;12(1):251.

15. Şahin AS, Türker G, Bekar A, Bilgin H, Korfalı G. A comparison of spinal anesthesia characteristics following intrathecal bupivacaine or levobupivacaine in lumbar disc surgery. European Spine Journal. 2014 Mar 1;23(3):695-700.

16. Mantouvalou M, Ralli S, Arnaoutoglou H, Tziris G, Papadopoulos G. Spinal anesthesia: comparison of plain ropivacaine, bupivacaine and levobupivacaine for lower abdominal surgery.

Acta
AnaesthesiologicaBelgica. 2008 Jan 1;59(2):65-71.

17. del-Rio-Vellosillo M, Garcia-Medina JJ, Abengochea-Cotaina A, Pinazo-Duran MD, Barbera-Alacreu M. Spinal anesthesia for knee arthroscopy using isobaric bupivacaine and levobupivacaine: anesthetic and neuroophthalmological assessment. BioMed research international. 2014 Jan 1;2014:1-7.

18. Vanna O, Chumsang L, Thongmee S. Levobupivacaine and bupivacaine in spinal anesthesia for transurethral endoscopic surgery. J Med Assoc Thai. 2006 Aug;89(8):1133-9.

19. Attri JP, Kaur G, Kaur S, Kaur R, Mohan B, Kashyap K. Comparison of levobupivacaine and levobupivacaine with fentanyl in infraumbilical surgeries under spinal anaesthesia. Anesthesia, essays and researches. 2015 May;9(2): 178.

20. Sanansilp V, Trivate T, Chompubai P, Visalyaputra S, Suksopee P, Permpolprasert L, von Bormann B. Clinical characteristics of spinal levobupivacaine: hyperbaric compared with isobaric solution. The Scientific World Journal. 2012 Jan 1;2012:1-7.

21. Sen H, Purtuloglu T, Sizlan A, Yanarates O, Ates F, Gundu I, Ozkan S, Dagli G. Comparison of intrathecal hyperbaric and isobaric levobupivacaine in urological surgery. Minerva Anestesiologica. 2010 Jan 1;76(1):24-8.

22. Glaser C, Marhofer P, Zimpfer G, Heinz MT, Sitzwohl C, Kapral S et al. Levobupivacaine versus racemic bupivacaine for spinal anesthesia. Anesthesia\& Analgesia. 2002 Jan 1;94(1):194-8.

23. Gonter AF, Kopacz DJ. Spinal 2chloroprocaine: a comparison with procaine in volunteers. AnesthAnalg. 2005;100(2):573-9

24. Smith KN, Kopacz DJ, McDonald SB. Spinal 2-chloroprocaine: a dose-ranging 
study and the effect of added epinephrine. AnesthAnalg. 2004;98(1):81-8

25. Cuvas O, Basar H, Yeygel A, Turkyilmaz E, Sunay MM. Spinal anesthesia for transurethral resection operations: levobupivacaine with or without fentanyl. Middle East journal of anaesthesiology. 2010 Feb 1;20(4):547-52.

26. Danelli G, Baciarello M, Di Cianni S, Zasa M, De Marco G, Adamanti S et al. Effects of baricity of $0.5 \%$ or $0.75 \%$ levobupivacaine on the onset time of spinal anesthesia: a randomized trial. Canadian Journal of Anesthesia. 2008;55(8):501-6.

27. Burke D, Kennedy S, Bannister J. Spinal anesthesia with $0.5 \% \mathrm{~S}(-)$-bupivacaine for elective lower limb surgery. Regional Anesthesia and Pain Medicine. 1999 Nov 1;24(6):519-23.

28. Fattorini F, Ricci Z, Rocco A, Romano R, Pascarella MA, Pinto G. Levobupivacaine versus racemic bupivacaine for spinal anaesthesia in orthopaedic major surgery. Minerva anestesiologica. 2006;72(7-8):63744.

29. Vath JS, Kopacz DJ. Spinal 2chloroprocaine: the effect of added fentanyl. Anesthesia\& Analgesia. 2004 Jan 1;98(1):89-94.

30. Kouri M, Kopacz DJ. Spinal 2chloroprocaine: a comparison with lidocaine in volunteers. AnesthAnalg. 2004;98(1):7580 .

31. Teunkens A, Vermeulen K, Van Gerven E, Fieuws S, Van de Velde M, Rex S. Comparison of 2-chloroprocaine, bupivacaine, and lidocaine for spinal anesthesia in patients undergoing knee arthroscopy in an outpatient setting: a double-blind randomized controlled trial. Regional Anesthesia\& Pain Medicine. 2016 Sep 1;41(5):576-83. 